\title{
Fortification of sunflower and palm oils using beta carotene extracted from Asystasia mysorensis and Solanum nigrum
}

\author{
Nderitu, S.M., "Nawiri, M.P. and Nyambaka, H.N. \\ Kenyatta University, P.O. Box 438944-00100, Nairobi, Kenya
}

Article history:

Received: 13 March 2018

Received in revised form: 5

June 2018

Accepted: 9 June 2018

Available Online: 3 July 2018

\section{Keywords:}

Edible oils,

Beta carotene,

Indigenous vegetables,

Fortification

\section{DOI:}

https://doi.org/10.26656/fr.2017.2(5).080

\begin{abstract}
In Kenya, indigenous vegetables such as Solanum nigrum (S. nigrum) and Asystasia mysorensis (A. mysorensis) are locally available but grossly underutilized. While the vegetables are a rich source of beta carotene (BC), a provitamin A carotenoid essential for mitigating vitamin A deficiency, they are highly perishable. Extractable BC quickly degrades in the presence of oxygen, light, and heat and therefore cannot be stored by itself. To address this antagonism, BC was extracted from S. nigrum and A. mysorensis and fortified in edible oils, sunflower and palm oils for 180 days. The peroxide and acid values of the oils were titrimetrically determined while RP-HPLC was employed for BC analysis. Peroxide values increased significantly $(\mathrm{p}<0.001)$ by $74.05 \%$ and $20 \%$, while acid values increase by $88.23 \%$ and $345 \%$ in sunflower and palm oils respectively over a 1 month period. Although the mean levels of BC reduced significantly $(p<0.001)$ by over $65 \%$ for the entire storage period, the levels of $\mathrm{BC}$ remaining were within the recommended daily allowance (RDA), implying that $\mathrm{BC}$ can be fortified in sunflower and palm oils to address the antagonism of its storage and degradation.
\end{abstract}

\section{Introduction}

Dark green leafy vegetables are rich sources of the fat-soluble pro-vitamin A carotenoid, beta carotene (BC) (Nyambaka and Ryley, 2001; Rodriguez-Amaya and Kimura, 2004; Stahl and Sies, 2005; Nawiri et al., 2013). Vitamin $\mathrm{A}$ is an essential nutrient needed in small amounts for the normal functioning of the visual system, growth, and development and is an antioxidant that would protect against the growth of cancerous cells (Young and Lowe, 2001; Stahl and Sies, 2005). Over the years, Vitamin A deficiency (VAD) is reported as the single most important cause of childhood blindness in developing countries (West Jr. and Darnton-Hill, 2008). Consumption of fruits and vegetables has been associated therefore with reduced cases of VAD and related illnesses (Codjia, 2001).

Kenya is home to more than 210 species of African Indigenous Vegetables (AIVs), most of which are underutilized such as black nightshade (Solanum nigrum), cowpeas (vigna unguiculata), spider plant (cleome gynandra) and Asystasia mysorensis (Mbugua et al., 2006). The AIVs are considered superior for the source of both human nutrition and for medicinal value. However, their nutritional and medicinal contribution depends on factors such as variety, climate, maturity, harvesting and postharvest handling and the plant part (Rodriguez-Amaya and Kimura, 2004). Further, the availability of AIVs is season dependent, being plenty during the rainy season and hence posing a challenge to their perishability due to limited preservation techniques and consequently the loss of BC. Preservation methods such as refrigeration, canning and drying that are employed to address vegetable perishability are not reached by the poor in developing counties. Preservation procedures create an additional challenge for $\mathrm{BC}$ since it degrades in the presence of oxygen, light, and heat (Moura et al., 2015). We visualized extraction of the carotenoid and its fortification in various matrices as mitigation to its degradation. In a similar study, Mungai et al. (2017) reported a 10\% retention of beta carotene extracted from Amaranthus spp and preserved in virgin coconut oil and unadulterated honey for 180 days. The study recommended an increase in the amounts of BC in the fortification matrices for higher retentions. Similarly, $\mathrm{BC}$ content in oven-dried cassava reduced from $72 \%$ to $32 \%$ after four weeks of storage at room temperature although high retentions of $70 \%$ were recorded when BC was encapsulated in phospholipids and stored in vacuum at normal room temperatures (Moura et al., 2015)

The edible vegetable oils, sunflower and palm oils 
are triglycerides, natural products of plant origin consisting of ester mixtures derived from glycerol with chains of fatty acids. Their degree of unsaturation is higher in sunflower than in palm oil, as indicated by their iodine value (IV) (Dauqan et al., 2011). The polyunsaturated fatty acids in vegetable oils are prone to oxidative and hydrolytic rancidity giving peroxides and other compounds that give oils objectionable odour (Kamau and Nanua, 2008). Light, heat, the composition of fatty acids, contact with oxygen and minor compounds (metals, pigments, phospholipids, free fatty acids, mono- and diacylglycerols, thermally oxidized compounds, and antioxidants) determine the extent of oxidation. Peroxide values of up to $10 \mathrm{mEq} / \mathrm{kg}$ of active oxygen $/ \mathrm{kg}$ and acid values of $0.6 \mathrm{mg} \mathrm{KOH} / \mathrm{g}$ are commended (Codex Alimentarius Commission, 1999). Choe and Min (2006) showed that oxidation of one gram of soybean oil which dissolved $55 \mu \mathrm{g}$ oxygen at room temperature gave a peroxide value of approximately 10 $\mathrm{mEq} / \mathrm{kg}$ in the dark. Other than peroxide values, acid values and thiobarbituric acid values are useful parameters in assessing the extent of spoilage or deterioration in vegetable oils. Semi-refined sunflower oil packed in containers with a headspace increase their peroxide values from $0.75-6.66 \mathrm{mEq} / \mathrm{kg}$ and full 0.75 $2.92 \mathrm{mEq} / \mathrm{kg}$ respectively for one month Kamau and Nanua (2008). Although peroxidation encourages oxidation of $\mathrm{BC}$, edible oils eventually stabilize $\mathrm{BC}$ and consequently slow down its degradation (Choe and Min, 2006). It was envisioned that BC extracted from $S$. nigrum and $A$. mysorensis would be fortified in sunflower and palm oils to contribute to the scientific investigations on fortification of this valuable carotenoid.

\section{Materials and methods}

\subsection{Chemicals and reagents}

Glacial acetic acid, chloroform, potassium iodide, soluble starch, sodium thiosulfate, phenolphthalein, and potassium hydroxide were purchased from Kobian Kenya limited. All the other chemicals used including beta carotene standard, acetonitrile, methanol, dichloromethane and other solvents were of analytical grade purchased from Sigma Chemicals Company (USA).

\subsection{HPLC specifications}

Separation was performed using HPLC (Shimadzu Prominence LC-20A) with a LC-20AD pump and UVVIS SPD-20VA deuterium lamp detector. Samples were injected on to a Gemini-NX 18110 A column $(5 \mu \mathrm{m} ; 250$ $\times 4.6 \mathrm{~mm})$ at $30^{\circ} \mathrm{C} .1 \mu \mathrm{L}$ volumes of standard and samples were injected and allowed 20 minutes elution time. A mobile phase consisting of Acetonitrile:
Methanol: Dichloromethane (70:10:20) was isocratically eluted at a flow rate of $0.8 \mathrm{~mL} \backslash \mathrm{min}$.

\subsection{Sampling and pretreatment}

The AIVs A. mysorensis and $S$. nigrum were randomLy sampled from five vendors (to make approximately $600 \mathrm{~g}$ of a homogenegized sample) at Githurai market, Nairobi County and transported to Kenyatta University Department of Chemistry Laboratory. The vegetables were washed thoroughly using distilled before weighing $500 \mathrm{~g}$ sample for extraction. Sunflower and palm oils that had been manufactured two weeks prior were purchased from stores in Nairobi County.

\subsection{Peroxide and acid value determination}

Sunflower and palm oils were stored at room temperature while a control experiment was done in limited atmospheric oxygen. For a period of 28 days, oil containers were opened daily for five seconds simulating the daily activity in the kitchen. AOCS Cd 8-53 method was followed for peroxide value determination (Steltzer, 2012). Five (5) $\mathrm{g}$ of vegetable oil was dissolved in $30 \mathrm{~mL}$ of glacial acetic acid: chloroform solution (3:2). Exactly $0.5 \mathrm{~mL}$ of saturated potassium iodide solution was added and the flask stoppered with occasional shaking of the mixture. After exactly 1 minute, $30 \mathrm{~mL}$ of distilled water was added and the headspace flushed with nitrogen. Three drops of $1 \%$ starch solution were added to produce a bluish purple colour. The solution was then titrated with $0.01 \mathrm{~N}$ sodium thiosulfate until the blue colour disappears. Peroxide values were calculated using Equation 1.

$$
\mathrm{PV}=\frac{1000 \times \mathrm{Vs} \times \mathrm{Ns}}{\mathrm{g}}
$$

Where

$\mathrm{PV}$ is peroxide value in $\mathrm{mEq} / \mathrm{kg}$ of vegetable oil

$\mathrm{Vs}$ is the volume of $\mathrm{Na}_{2} \mathrm{SO}_{3}$ used in the vegetable oil sample until yellow colour fades $(\mathrm{mL})$

$\mathrm{Ns}$ is the normality of $\mathrm{Na}_{2} \mathrm{SO}_{3}(\mathrm{mEq} / \mathrm{mL}$ used for titration)

$\mathrm{g}$ is the mass of vegetable oil sample used in grams

To measure acid value, exactly $2.5 \mathrm{~g}$ of oil was dissolved in $25 \mathrm{~mL}$ of petroleum ether in a flask and heated on a steam bath for 2 minutes before 2 drops of phenolphthalein indicator were added. The solution was titrated with $0.1 \mathrm{~N}$ potassium hydroxide until a pink colour appeared. Acid values were calculated using Equation 2

$$
\mathrm{AV}=\frac{\mathrm{Vs} \times \mathrm{Ns} \times 56.1}{\mathrm{~g}}
$$

Where

$\mathrm{AV}$ is acid value in $\mathrm{mg} \mathrm{KOH} / \mathrm{g}$ in vegetable oil sample. 
Vs is the volume of potassium hydroxide $(\mathrm{KOH})$ used in the vegetable oil sample until pink colour appears $(\mathrm{mL})$.

$\mathrm{Ns}$ is the normality of $\mathrm{KOH}$

56.1 is the molecular weight of $\mathrm{KOH}$.

$\mathrm{g}$ is the mass of vegetable oil sample in grams.

\subsection{Preparation of calibration curve}

Stock solution for beta carotene was prepared by dissolving $1 \mathrm{mg}$ of pure beta carotene standard in exactly $2 \mathrm{~mL}$ of methanol to make $0.5 \mathrm{mg} / \mathrm{mL}(500 \mathrm{ppm})$ of solution. Five serial working standard solutions of 250 , $125,62.5$ and $31.25 \mathrm{ppm}$ were prepared through dilution of stock solution and used to prepare calibration on HPLC. The series of standards were injected in triplicates to evaluate the reproducibility of the detector.

\subsection{Extraction of beta carotene}

The method by Rodriguez-Amaya and Kimura (2004) was adopted with slight modifications. Vegetable leaves were blanched in hot water at $90^{\circ} \mathrm{C}$ for 3 minutes then blended with celite powder to a smooth paste. Exactly $20 \mathrm{~g}$ of the homogeneous paste was placed in a conical flask and $50 \mathrm{~mL}$ cold acetone added. The mixture was sonicated for 10 minutes and filtered using a Buchner funnel. This procedure was repeated until there was no more colour change to the residue. Exactly 25 $\mathrm{mL}$ of petroleum ether (PE) was placed in a separating funnel and $10 \mathrm{~g}$ of butylated hydroxytoluene (BHT) added. Small portions of the acetone extract were added at a time until all the extract was transferred to PE. Distilled water was added slowly along the walls of the funnel and the two phases allowed to separate. The lower aqueous-acetone phase was discarded and washed repeatedly 5 times with distilled water to remove any residual acetone.

The PE extract was washed with $0.1 \%$ potassium hydroxide in ethanol and allowed to stand for 15 minutes to allow further separation before washing 5 more times with distilled water to remove impurities. The carotenoid layer collected was dried using anhydrous sodium sulphate and the solvent removed with a rotary evaporator at $30^{\circ} \mathrm{C}$. Solid beta carotene obtained was weighed accurately and then preserved in sunflower and palm oils.

\subsection{Fortification and analysis of beta carotene}

Exactly $425 \mathrm{mg}$ of the beta carotene extracted from A. mysorenis and $448 \mathrm{mg}$ were fortified in $15 \mathrm{~cm}^{3}$ sunflower and palm oils individually and separately. A homogenized mixture was made using a magnetic stirrer in a stream of nitrogen gas. Using a syringe the mixture was placed into eight $1.5 \mathrm{~cm}^{3}$ amber air-tight vial and kept at room temperature. The procedure was done in an environment with subdued light to prevent degradation. The amount of beta carotene was determined on the first day (day 1), and after 14, 30, 60, 90, 120, 150 and 180 days. For control, dry nitrogen was blown into 8 empty $1.5 \mathrm{~cm}^{3}$ dark bottles to drive out air and packed with extracted of beta carotene dissolved in petroleum ether under nitrogen. The amount of beta carotene in fortified samples was determined using HPLC conditions given in above.

\subsection{Data analysis}

SPSS package was used for data analysis. One way ANOVA was employed for significant differences between means of concentration and separation of means using multiple range tests (Student Newman Keul Test) was employed. The level of confidence $(\alpha)$ for all the values analyzed was all performed at $95 \%$.

\section{Results and discussion}

\subsection{Peroxide and acid values of oils}

The peroxide and acid values which indicate oxidative rancidity and hydrolytic rancidity respectively for the sunflower and palm oils are presented in Table 1.

Peroxide values obtained indicated lipid oxidation onset with values falling within the FAO recommended limits (Codex Alimentarius Commission, 1999). The values increased significantly $(\mathrm{p}<0.001)$ from $3.93 \pm 0.03$ to $6.84 \pm 0.04$ and $2.00 \pm 0.00$ to $2.40 \pm 0.00 \mathrm{mEq} / \mathrm{kg}$ oil in sunflower and palm oils respectively over 28 days. This increase, $74.05 \%$ and $20 \%$ in sunflower and palm oils

Table 1. Peroxide and acid values for sunflower and palm oils over 28 days

\begin{tabular}{ccccc}
\hline \multirow{2}{*}{ Days } & \multicolumn{2}{c}{ Peroxide values $(\mathrm{mEq} / \mathrm{Kg}$ oil $)(\mathrm{n}=3)$} & \multicolumn{2}{c}{ Acid value $(\mathrm{mg}$ in KOH/ g) $(\mathrm{n}=3)$} \\
\cline { 2 - 5 } & Sunflower oil & Palm oil & Sunflower oil & Palm oil \\
\hline 1 & $3.93 \pm 0.03^{\mathrm{a}}$ & $2.00 \pm 0.00^{\mathrm{a}}$ & $0.34 \pm 0.00^{\mathrm{a}}$ & $0.11 \pm 0.00^{\mathrm{a}}$ \\
2 & $4.80 \pm 0.00^{\mathrm{b}}$ & $2.10 \pm 0.00^{\mathrm{b}}$ & $0.41 \pm 0.04^{\mathrm{b}}$ & $0.19 \pm 0.04^{\mathrm{a}}$ \\
14 & $5.40 \pm 0.06^{\mathrm{c}}$ & $2.17 \pm 0.03^{\mathrm{c}}$ & $0.49 \pm 0.04^{\mathrm{c}}$ & $0.30 \pm 0.04^{\mathrm{b}}$ \\
21 & $6.03 \pm 0.03^{\mathrm{d}}$ & $2.27 \pm 0.03^{\mathrm{d}}$ & $0.56 \pm 0.00^{\mathrm{d}}$ & $0.37 \pm 0.04^{\mathrm{b}}$ \\
28 & $6.84 \pm 0.04^{\mathrm{e}}$ & $2.40 \pm 0.00^{\mathrm{e}}$ & $0.64 \pm 0.04^{\mathrm{e}}$ & $0.49 \pm 0.04^{\mathrm{c}}$ \\
p-value & $<0.001$ & $<0.001$ & $<0.001$ & $<0.001$ \\
\hline
\end{tabular}

Values are mean \pm SD. Mean values followed by the same letter(s) within the same column do not differ significantly from one another. (One-way ANOVA, SNK-test, $\alpha=0.05$ ) 
Table 2. The mean levels of beta carotene fortified in sunflower and palm oils.

\begin{tabular}{|c|c|c|c|c|c|c|}
\hline \multirow{3}{*}{ Days } & \multicolumn{6}{|c|}{ Concentration $\mathrm{mg} / 100 \mathrm{~g}$ DM $(\mathrm{n}=3)$} \\
\hline & \multicolumn{3}{|c|}{ A. mysorensis } & \multicolumn{3}{|c|}{ S. nigrum } \\
\hline & Nitrogen & Sunflower oil & Palm oil & Nitrogen & Sunflower oil & Palm oil \\
\hline 1 & $24.85 \pm 0.002$ & $24.83 \pm 0.002^{\mathrm{a}}$ & $24.82 \pm 0.001^{\mathrm{a}}$ & $41.49 \pm 0.02$ & $41.48 \pm 0.003^{\mathrm{a}}$ & $41.46 \pm 0.003^{\mathrm{a}}$ \\
\hline 14 & $24.82 \pm 0.007$ & $23.58 \pm 0.008^{\mathrm{b}}$ & $23.49 \pm 0.001^{\mathrm{b}}$ & $41.44 \pm 0.07$ & $35.55 \pm 0.003^{b}$ & $40.42 \pm 0.003^{\mathrm{a}}$ \\
\hline 30 & $24.78 \pm 0.003$ & $18.61 \pm 0.002^{\mathrm{c}}$ & $20.58 \pm 0.002^{\mathrm{c}}$ & $41.38 \pm 0.03$ & $27.62 \pm 0.002^{\mathrm{c}}$ & $35.20 \pm 0.002^{b}$ \\
\hline 60 & $24.61 \pm 0.001$ & $15.38 \pm 0.001^{\mathrm{d}}$ & $18.89 \pm 0.001^{\mathrm{d}}$ & $41.21 \pm 0.01$ & $21.82 \pm 0.003^{\mathrm{d}}$ & $30.38 \pm 0.001^{\mathrm{c}}$ \\
\hline 90 & $24.50 \pm 0.003$ & $12.89 \pm 0.001^{\mathrm{e}}$ & $15.24 \pm 0.002^{\mathrm{e}}$ & $41.10 \pm 0.03$ & $16.81 \pm 0.002^{\mathrm{e}}$ & $26.09 \pm 0.002^{\mathrm{d}}$ \\
\hline 120 & $24.38 \pm 0.002$ & $10.16 \pm 0.002^{\mathrm{f}}$ & $12.38 \pm 0.002^{\mathrm{f}}$ & $40.98 \pm 0.02$ & $13.07 \pm 0.003^{\mathrm{f}}$ & $19.65 \pm 0.001^{\mathrm{e}}$ \\
\hline 150 & $24.25 \pm 0.004$ & $7.42 \pm 0.002^{\mathrm{g}}$ & $9.74 \pm 0.002^{\mathrm{g}}$ & $40.65 \pm 0.20$ & $8.91 \pm 0.003^{\mathrm{g}}$ & $17.51 \pm 0.002^{f}$ \\
\hline 180 & $24.05 \pm 0.008$ & $6.67 \pm 0.002^{\mathrm{h}}$ & $8.45 \pm 0.001^{\mathrm{h}}$ & $40.14 \pm 0.08$ & $7.65 \pm 0.003^{\mathrm{g}}$ & $14.28 \pm 0.001^{\mathrm{g}}$ \\
\hline $\mathrm{p}$-value & $>0.05$ & $<0.001$ & $<0.001$ & $>0.05$ & $<0.001$ & $<0.001$ \\
\hline
\end{tabular}

Values are mean \pm SD. Mean values followed by different letters are significantly different $(\alpha=0.05)$, One-way ANOVA, SNK-test
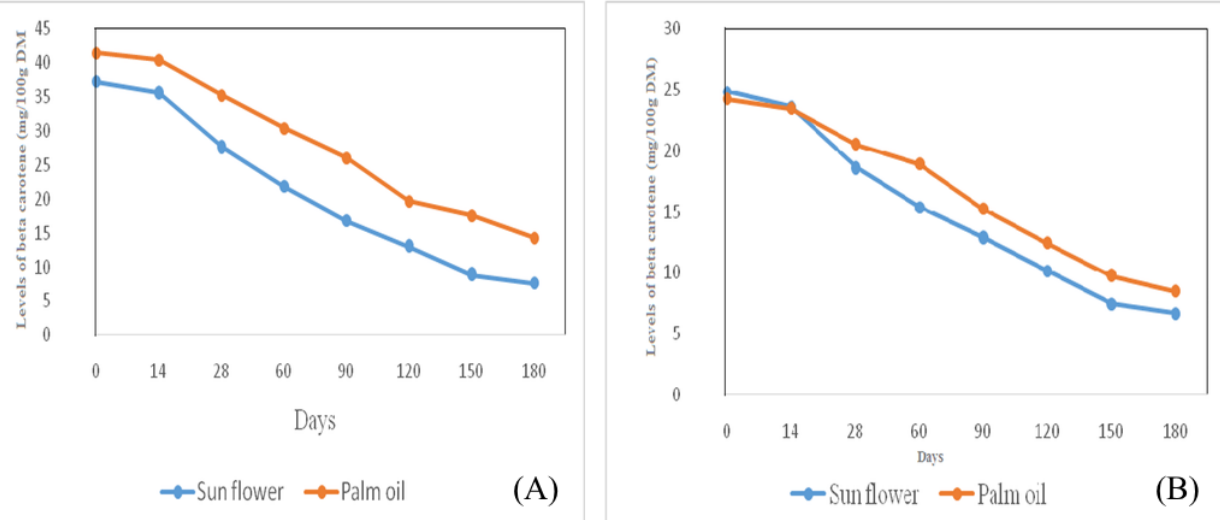

Figure 1. Trend of mean levels of beta carotene stored in sunflower and palm oils over 180 days. S. nigrum (A); A. mysorensis (B)

respectively are attributed to oxidation of unsaturation lipids in the presence of oxygen and light, although the initiation effect of autoxidation and photosensitized oxidation during processing may not be ignored (Choe and Min, 2006). Peroxide values increased more in sunflower than palm oil possibly due to the differences in lipids. Oils such as sunflower with IV $>130$ have higher unsaturation are more oxidized than palm oil with IV $<20$ (Tan et al., 2002; Packer et al., 2005; Kamau and Nanua, 2008). The nature of packing, transparent packs against opaque plastic containers has shown to influence levels of peroxide values (Velasco and Dobarganes, 2002).

The acid values increased from $0.34 \pm 0.00$ to $0.64 \pm 0.04(88.23 \%)$ and $0.11 \pm 0.00$ to $0.49 \pm 0.04$ $(345.45 \%) \mathrm{mg}$ in $\mathrm{KOH} / \mathrm{g}$ for in sunflower and Palm oils respectively. This increase in hydrolytic rancidity was found to be significant $(p<0.001)$ although values were within the FAO recommended limits (Codex Alimentarius Commission, 1999). Moisture and lipolytic enzymes in oils influence increase in acid values (Kamau and Nanua, 2008).

\subsection{Beta carotene retention in vegetable oils}

The levels of beta-carotene retained in sunflower and palm oils over a period of 180 days and the trend is presented in Table 2 and Figure 1 respectively.

The AIVs, A. mysorensis, and S. nigrum contained $24.83 \pm 0.02$ and $24.82 \pm 0.001$ for sunflower and palm oils while $41.48 \pm 0.003$ and $41.46 \pm 0.003 \mathrm{mg} / 100 \mathrm{~g} \mathrm{DM}$ of BC before fortification. These levels translate to $1.91 \pm 0.001$ and $1.863 \pm 0.0001,2.860 \pm 0.0002$ and $3.19 \pm 0.001$ retinol activity equivalent (RAE) respectively. On fortification in sunflower oil, the mean levels of BC extracted from $A$. mysorensis decreased to a level of $6.67 \pm 0.002 \mathrm{mg} / 100 \mathrm{~g}$ DM (73.14\%). In palm oil, a $65.95 \%$ reduction was observed to a level of $8.45 \pm 0.001 \mathrm{mg} / 100 \mathrm{~g} \mathrm{DM}$ by the $180^{\text {th }}$ day. Similarly, mean levels of BC extracted from $S$. nigrum reduced significantly $(\mathrm{P}<0.001)$ when fortified in sunflower (18.44\% reduction) and palm oils (34.44\%). After 180 days, the RAE in sunflower and palm oils stood at $0.513 \pm 0.0002$ and $0.650 \pm 0.0001$, for $A$. mysorensis and $0.588 \pm 0.0002$ and $1.098 \pm 0.0001$ for $S$. nigrum. Recommended daily allowance (RDA) for vitamin A falls within the range of $400 \mu \mathrm{g}$ for infants to $1300 \mu \mathrm{g}$ for adults (Canada Health, 2014).

The trends showed lowest reductions $(p<0.001)$ during the first 14 days (Figure 1). During this period the peroxide and acid values of the oils were also low (Table 
1). Lower reductions of the carotenoid, however, have been shown in oven-dried cassava storage at room temperature (Moura et al., 2015) Due to conjugation nature in $\mathrm{BC}$ molecule, degradation is inevitable with oxygen, heat, acids, free radicals and other components in the preservation matrices (Rodriguez-Amaya, 2001; Moura et al., 2015). Sunflower and palm oils are known to contain palmitic, stearic, oleic, linoleic and traces of free fatty acids (Choe and Min, 2006). There was a significantly higher level of $\mathrm{BC}$ in the fortified palm oil than in sunflower oil $(p<0.001)$, which was attributed to the higher peroxide and acid values. Increased peroxide and acid values of the oils with time affected the beta carotene retained. This is evident from the correlation coefficients of peroxide and acid values of sunflower and palm oils whose values were $\mathrm{R}^{2}=0.854,0.908$ and 0.839 , 0.850 for $\mathrm{BC}$ extracted from A. mysorensis and $\mathrm{R}^{2}=$ $0.837,0.856$ and $0.966,0.873$ for BC extracted from $S$. nigrum respectively.

\section{Conclusion}

The peroxide and acid values of sunflower and palm oils increased significantly over a period of 28 days indicating that the oils rapidly deteriorate. This contributed to the low retention of beta carotene extracted from $A$. mysorensis and $S$. nigrum indigenous vegetables when fortified in the oils. The retained amounts of $\mathrm{BC}$, however, were still sufficient to provide recommended daily allowance (RDA). These findings reveal may suggest a potential of using the edible oils sunflower and palm oils as matrices for fortifying BC, although further studies on the control of oxidative rancidity and hydrolytic rancidity of the oils is required.

\section{References}

Canada Health. (2014). Health Canada's Proposed Changes to the Daily Values (DVs) for Use in Nutrition Labelling. Canada: Bureau of Nutritional Sciences, Food Directorate, Health Products and Food Branch.

Choe, E. and Min, D.B. (2006). Mechanisms and Factors for Edible Oil Oxidation. Comprehensive Reviews in Food Science and Food Safety, 5, 169-186. https:// doi.org/10.1111/j.1541-4337.2006.00009.x

Codex Alimentarius Commission. (1999). Codex Standards for Fats and Oils from Vegetable Sources. In The Codex Alimentarius. Vol. 8, $2^{\text {nd }}$ Ed. Rome: Joint FAO/WHO Food Standards Programme, FAO.

Codjia, G. (2001). Food sources of vitamin A and provitamin A specific to Africa: an FAO perspective. Food and Nutrition Bulletin, 22, 357-360. https:// doi.org/10.1177/156482650102200403
Dauqan, E.M., Sani, H.A., Abdullah, A. and Kasim, Z.M. (2011). Fatty acids composition of four different vegetable oils (red palm olein, palm olein, corn oil and coconut oil) by gas chromatography. 2nd International Conference on Chemistry and Chemical Engineering, p. 31-34. Singapore: IACSIT Press.

Kamau, J.M. and Nanua, J.N. (2008). Storage stability of ram press extracted semi-refined sunflower oil. Agricultura Tropicaet Subtropica, 41(3), 106-109.

Mbugua, G., Gitonga, L.N., Mureithi, E., Karoga, J. and Manyeki, L. (2006). Farmer-Participatory prioritization and development of agronomic practices for African Leafy Vegetables. Proceedings of $5^{\text {th }}$ Workshop on Sustainable Horticultural Production in the Tropics, $23^{\text {rd }}-26^{\text {th }}$ November 2005, Egerton University, Kenya, p. 152-166. Kenya: Horticultural Association of Kenya.

Moura, F.F.D., Miloff, A. and Boy, E. (2015). Retention of Provitamin a Carotenoids in Staple Crops Targeted for Bio fortification in Africa: Cassava, Maize and Sweet Potato. Critical Reviews in Food Science and Nutrition, 55(9), 1246-1269. https:// doi.org/10.1080/10408398.2012.724477

Mungai, Z.M., Nawiri, M.P. and Nyambaka, H.N. (2017). Retention levels of vegetable extractable beta -carotene preserved in virgin coconut oil and unadulterated honey. Food Research, 1(5), 170-175. https://doi.org/10.26656/fr.2017.5.051

Nawiri, M.P., Nyambaka, H. and Murungi, J.I. (2013). Sun-dried cowpeas and amaranth leaves recipe improves $\beta$-carotene and retinol levels in serum and hemoglobin concentration among preschool children. European Journal of Nutrition, 52, 583-589. https:// doi.org/10.1007/s00394-012-0360-2

Nyambaka, H.N. and Ryley, J. (2001). Degradative provitamin $A$ active compounds of all-trans- $\beta$-carotene in dehydrated dark green leafy vegetables. Bulletin of the Chemical Society of Ethiopia, 15(1), 57-64. https://doi.org/10.4314/bcse.v15i1.71913

Packer, L., Obermueller-Jevic, U., Kraemer, K. and Sies, H. (2005). Carotenoids and retinoids: molecular aspects and health issues. US: CRC Press.

Rodriguez-Amaya, D.B. (2001). A guide to carotenoid analysis in foods. Washington, DC: ILSI press.

Rodriguez-Amaya, D.B. and Kimura, M. (2004). HarvestPlus handbook for carotenoid analysis. HarvestPlus Technical Monograph 2. Washington, DC: International Food Policy Research Institute (IFPRI) and International Center for Tropical Agriculture (CIAT)

Stahl, W. and Sies, H. (2005). Bioactivity and protective effects of natural carotenoids. Biochimica et 
Biophysica Acta (BBA), 1740(2), 101-107. https:// doi.org/10.1016/j.bbadis.2004.12.006

Steltzer, E.T. (2012). Evaluation of chemical assays for determining hydro peroxides levels in oxidized lipids. New Jersey: The State University of New Jersey, MSc Thesis.

Tan, C.P., Man, Y.C., Selamat, J. and Yusuf, M.S.A. (2002). Comparative studies of oxidative stability of edible oils by differential scanning calorimetry and oxidative stability index methods. Food Chemistry, 76(3), 385-389. https://doi.org/10.1016/S0308-8146 (01)00272-2

Velasco, J. and Dobarganes, C. (2002). Oxidative stability of virgin olive oil. European Journal of Lipid Science and Technology, 104(9-10), 661-676. https://doi.org/10.1002/1438-9312(200210) 104:9/10<661::AID-EJLT661>3.0.CO;2-D

West Jr., K.P. and Darnton-Hill, I. (2008). Vitamin A Deficiency. In Semba, R.D. and Bloem, M.W. Nutrition and health in developing countries. $2^{\text {nd }} \mathrm{Ed}$., p. 377-433. US: Humana Press. https:// doi.org/10.1007/978-1-59745-464-3_13

Young, A.J. and Lowe, G.M. (2001). Antioxidant and prooxidant properties of carotenoids. Archives of Biochemistry and Biophysics, 385(1), 20-27. https:// doi.org/10.1006/abbi.2000.2149 